Article

\title{
Study on the Microstructure of Polyester Polyurethane Irradiated in Air and Water
}

\section{Qiang Tian ${ }^{1,2}$, Erzsébet Takács ${ }^{3}$, Ivan Krakovský ${ }^{4}$, Zsolt Endre Horváth ${ }^{3}$, László Rosta ${ }^{2}$ and} László Almásy ${ }^{2, *}$

${ }^{1}$ Key Laboratory of Neutron Physics and Institute of Nuclear Physics and Chemistry, China Academy of Engineering Physics, Mianyang 621999, China; E-Mail: tqsuperego@163.com

${ }^{2}$ Wigner Research Centre for Physics, Budapest H-1525, Hungary;

E-Mail: rosta.laszlo@wigner.mta.hu

${ }^{3}$ Centre for Energy Research, Budapest H-1525, Hungary;

E-Mails: erzsebet.takacs@energia.mta.hu (E.T.); horvatze@mfa.kfki.hu (Z.E.H.)

${ }^{4}$ Department of Macromolecular Physics, Faculty of Mathematics \& Physics, Charles University, Prague 180 00, Czech Republic; E-Mail: ivan_krakovsky@yahoo.co.uk

* Author to whom correspondence should be addressed; E-Mail: almasy@ mail.kfki.hu;

Tel.: +36-1392-2222 (ext. 1447); Fax: +36-1392-2548.

Academic Editor: Yue Zhao

Received: 13 August 2015 / Accepted: 2 September 2015 / Published: 15 September 2015

\begin{abstract}
The gamma irradiation induced aging of thermoplastic polymer Estane 5703 in air and water environments was studied by small-angle neutron scattering (SANS), Fourier transform infrared spectroscopy (FTIR), gel permeation chromatography (GPC), and X-ray diffraction (XRD). The degree of phase mixing was increased after irradiation, accompanied by the increase of domain distance and decrease of domain size. The hard domain distance increased from 9.8 to $11.2 \mathrm{~nm}$ and $14.4 \mathrm{~nm}$ for the samples irradiated in air and water with a dose up to $500 \mathrm{kGy}$, respectively. The GPC results indicated progressive formation of larger linked structures with very high molar mass with increasing absorbed doses. The samples irradiated in water exhibited a stronger aging effect than those irradiated in air. The FTIR results suggested that the cross-linking occurred among the secondary alkyl radicals, and the interactions in hard domains weakened because of the loss of inter-urethane H-bonds. The volume fraction of well-ordered soft segments in Estane increased upon irradiation.
\end{abstract}

Keywords: polyurethane; irradiation; microstructure; phase mixing; SANS 


\section{Introduction}

Segmented polyurethanes (PUs) are a class of thermoplastic elastomers that bridge the gap between rubbers and plastics [1]. The superior properties of PUs originate in the thermodynamic incompatibility between the hard segments (HSs) and soft segments (SSs). PUs have wide applications in industrial, aerospace, and biomedical areas. When PUs are exposed to high energy irradiation, the structure and mechanical property may be altered. It is of importance from both basic and applied viewpoints to determine how the microstructure and stability could be influenced by irradiation.

Generally, PUs have shown higher radiation resistance compared with other common polymers, such as polyolefins and vinyl polymers [2,3]. However, the effects of irradiation on the microstructure are complex, and closely related to the chemical composition, irradiation environment, and absorbed dose. Shintani et al. [4] found that PUs chain extended with 1,4-butanediol (BDO) degrade, while those without BDO mainly undergo cross-linking by $\gamma$-ray irradiation. Pierpoint et al. [5] reported that Estane 5703 primarily undergoes rapid cross-linking, and partially undergoes scission reactions both in the presence and absence of oxygen after $\gamma$ or electron irradiation. Murray et al. [6] revealed a high level of cross-linking at $200 \mathrm{kGy}$ and an increase in phase segregation of Pelletane 2363-90A after irradiation. Burillo et al. [7] found that the tensile strength of polyester polyurethane was reduced by $50 \%$ with $310 \mathrm{kGy}$ absorbed dose, and adding diphenylbutadiyne could effectively suppress the polymer chain degradation. Sui et al. [8] studied $\gamma$-irradiation effects on a PU adhesive and revealed the degradation in the SSs composed of poly(ethyleneglycol adipate) with the dose up to $1000 \mathrm{kGy}$. As it is characteristic for polymers, chain scission and cross-linking are the two main reactions in PUs exposed to $\gamma$ irradiation.

It is widely accepted that the unique properties of PUs are closely related to their multi-phase microstructure, in which the hard domains act as physical cross-linking points and reinforcing fillers embedded in the soft matrix [9-11]. Therefore, the performance of irradiated PUs is not only determined by the chemical composition, but also strongly influenced by the microphase structure, such as domain size, spatial distribution, and degree of phase separation. From the point of view of applications of PUs it is vital to understand these effects. The small-angle scattering technique is ideally suited for investigating nanoscale morphology of materials. Morphological changes due to chemical reaction, microphase separation kinetics, temperature, and mechanical deformation can be effectively observed by scattering methods [12-16]. Up to now, little information is published on the microphase structure of irradiated PUs.

In this work, we focus on studying the domain structure of Estane (a commercially available thermoplastic PU) $\gamma$-irradiated both in air and water using small-angle neutron scattering (SANS) technique. Additionally, information on cross-linking, chemical reactions, and crystallization of SS is obtained by gel permeation chromatography (GPC), Fourier transform infrared spectroscopy (FTIR), and X-ray diffraction (XRD). A phase mixing behavior, for the first time, is observed in this class of polyester polyurethane systems. The effects of the water and air environments during irradiation on the microstructure of Estane are comparatively discussed. 


\section{Experimental Section}

\subsection{Materials}

Estane 5703 was obtained as pellets from the Lubrizol Advanced Materials, Inc., Westerlo-Ovel, Belgium. It is a segmented polyurethane copolymer, containing about 23 wt \% HSs, prepared by the reaction of 4,4'-diphenylmethane diisocyanate (MDI) and poly(butylene adipate) (PBA) with BDO as the chain extender. The SSs composed of PBA have an average molecular weight in the range of 800 to 1050 Da. The molecular structure of Estane is presented in Figure 1.

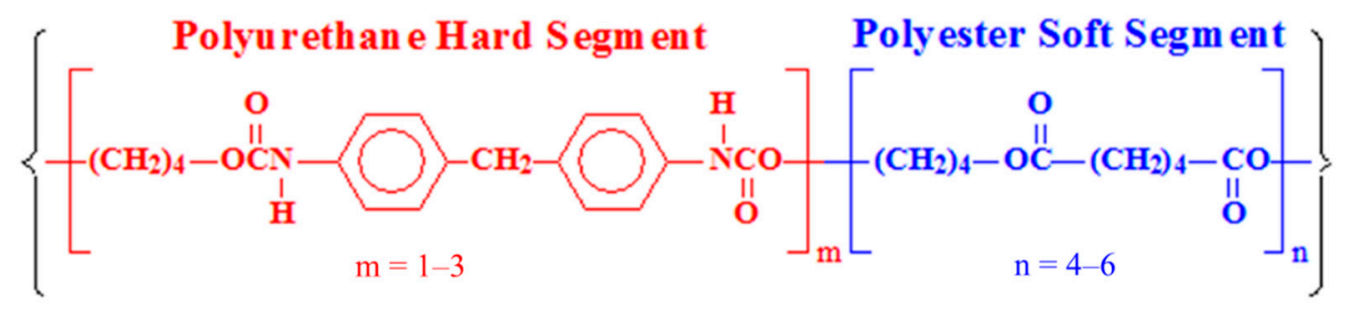

Figure 1. Molecular structure of Estane 5703.

Estane pellets were compression-molded into $1 \mathrm{~mm}$ thick film at $20 \mathrm{MPa}, 120{ }^{\circ} \mathrm{C}$ for $10 \mathrm{~min}$ and then cooled to room temperature (RT), initiating the phase separation process. The samples were stored at RT in a drying oven for two years before irradiation. The Estane samples were irradiated both in air and distilled water using ${ }^{60} \mathrm{Co} \gamma$ radiation source at doses of 50, 100, 200, 300 and $500 \mathrm{kGy}$ with a dose rate of $3.9 \mathrm{kGy} / \mathrm{h}$ at Centre for Energy Research, Budapest, Hungary. The samples $(10 \mathrm{~mm} \times 10 \mathrm{~mm} \times 1 \mathrm{~mm})$ were placed in glass tube holders with diameter of $20 \mathrm{~mm}$ and wall thickness of about $1 \mathrm{~mm}$, filled with air or distilled water.

\subsection{Characterization}

The SANS measurements were performed on the small-angle neutron scattering diffractometer Yellow Submarine at the Budapest Research Reactor (BNC, Budapest, Hungary). The scattering intensity $I(q)$ is measured as a function of scattering vector $q=4 \pi \sin \theta / \lambda$, where $\lambda$ is the wavelength of the incident neutrons, and $\theta$ is half of the scattering angle. The monochromatic beam with a mean wavelength of $0.47 \mathrm{~nm}$ and 0.2 FWHM had been produced by a multidisk mechanical velocity selector (KFKI, Budapest, Hungary). $\mathrm{A} \mathrm{BF}_{3}$ gas filled multiwire detector of $64 \mathrm{~cm} \times 64 \mathrm{~cm}$ sensitive area was placed at distance of $5.5 \mathrm{~m}$ from the sample, to cover the $q$-interval of $0.1-0.9 \mathrm{~nm}^{-1}$. The total data acquisition time for each sample was about $6 \mathrm{~h}$. The scattering data were processed using BerSANS software (Hahn-Meitner-Institut, Berlin, Germany) [17]. The data reduction corrects the raw measured data for the contributions of the background, transmission, and scattering from the tape used for fixing the samples. All the data were fitted by SASfit software (Paul Scherrer Institute, Villigen, Switzerland), and the $q$-resolution has been taken into account by convoluting the theoretical curve with the instrument resolution function [18].

The gel permeation chromatography (GPC) measurements were performed using a Biospher GMB 100 column $(8 \mathrm{~mm} \times 500 \mathrm{~mm}$, Labio, Czech Republic) filled with $10 \mu \mathrm{m}$ sorbent particles. Tetrahydrofuran (Sigma-Aldrich, St. Louis, MO, USA), distilled and dried over molecular sieves (4 Å), 
was used as a mobile phase at a flow rate $1 \mathrm{~mL} / \mathrm{min}$. Small amount of toluene $(2 \%(w / v))$ was used as internal standard. Concentration of all PU solutions subjected to GPC analysis was $2.00 \%(w / v)$. The data from a refractive index detector were collected and treated by using CSW 1.7 software (DataApex, Prague, Czech Republic). For the determination of molar masses, a universal calibration equation calculated from the data on polystyrene standards (Polymer Standards Service) was used. The lower limit for resolution (total exclusion limit) of the chromatographic column used is about $9.5 \mathrm{~mL}$. This means that polymer species (linear or branched) with molar mass higher than $c a$. 1,000,000 g/mol are not resolved by the column. Fourier transform infrared spectroscopy (FTIR) was taken by a Unicam Mattson Research Series 1 FTIR spectrometer (Unicam Mattson, London, UK). The crystalline structure of the samples was determined by XRD, using a Bruker AXS D8 Discover diffractometer (Bruker AXS, Karlsruhe, Germany) equipped with a Göbel mirror and a scintillation detector using $\mathrm{Cu} K_{\alpha}$ radiation.

\section{Results}

\subsection{Small-Angle Neutron Scattering (SANS)}

The $I(q)$ curves of original (labeled as $0 \mathrm{kGy}$ ) and irradiated Estane are shown in Figure 2. All the curves display a broad interference peak, which suggests a broader distribution of the interdomain distance throughout the samples. The peaks shift toward lower $q$ and become less distinct with increasing the absorbed dose, indicating that the interdomain association is weakened and the most probable domain distance is increased.
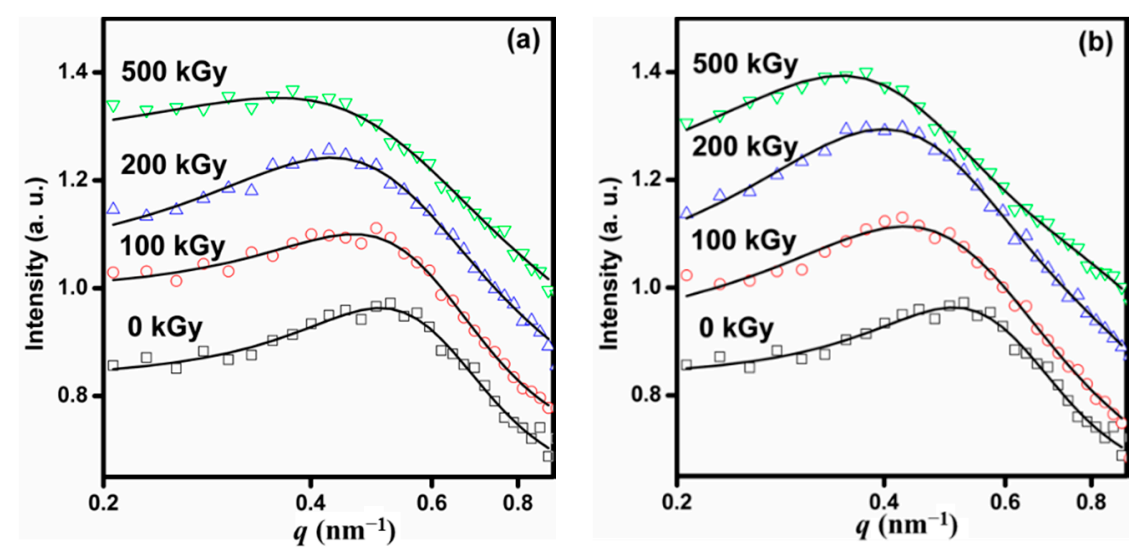

Figure 2. SANS data of the $\gamma$-ray irradiated Estane samples at absorbed doses of 0,100 , 200 and $500 \mathrm{kGy}$ in air (a) and water (b).

In order to get more information, we applied the Debye-Anderson-Brumberger (DAB) form factor $P\left(q, a_{\text {cor }}\right)$ plus Percus-Yevick (PY) structure factor as an approximate model to fit the scattering intensities by equation:

$$
I(\mathbf{q})=K \times P\left(q, a_{\mathrm{cor}}\right) \times S\left(q, R_{\mathrm{HS}}, v\right)+I_{\mathrm{B}}
$$

where $R_{\mathrm{HS}}$ and $v$ denote the hard sphere interaction radius and volume fraction, $a_{\text {cor }}$ is the length over which the structural correlation decays and can be considered as the average size of hard domains because of the low HSs content in Estane, $K$ is a scale factor, and $I_{\mathrm{B}}$ is a constant which accounts for the incoherent scattering [16,19-21]. The fitting parameters are listed in Table 1. The hard domain 
distance, expressed by $2 R_{\mathrm{HS}}$, increases from 9.8 to $11.2 \mathrm{~nm}$ and $14.4 \mathrm{~nm}$ for the samples irradiated in air and water with a dose up to $500 \mathrm{kGy}$ (Figure 3), respectively. Hence the samples irradiated in water exhibit stronger structure changes. The number density of the hard domains, proportional to $v / R_{\mathrm{Hs}}{ }^{3}$, is decreased gradually with dose (Table 1). The results suggest that the increase in domain distance is caused by the decrease in number density of the hard domains. The hard sphere volume fraction $v$ decreases with increasing dose as well, indicating that a part of HSs are dissolved into soft domains induced by irradiation.

Table 1. Structural parameters obtained from SANS data on irradiated Estane samples by curve-fitting using the DAB-PY model.

\begin{tabular}{ccccc}
\hline Samples & $\boldsymbol{R}_{\mathbf{H S}}(\mathbf{n m})$ & $\boldsymbol{a}_{\mathbf{c o r}}(\mathbf{n m})$ & $\boldsymbol{v}$ & $\left.\boldsymbol{v} / \boldsymbol{R}_{\mathbf{H S}} \mathbf{3}^{\mathbf{n m}} \mathbf{n m}^{-\mathbf{3}}\right)$ \\
\hline Original & $4.9 \pm 0.1$ & $1.8 \pm 0.3$ & $0.21 \pm 0.03$ & $1.8 \times 10^{-3}$ \\
$100 \mathrm{kGy}$ in air & $5.0 \pm 0.1$ & $1.7 \pm 0.2$ & $0.18 \pm 0.02$ & $1.4 \times 10^{-3}$ \\
$200 \mathrm{kGy}$ in air & $5.5 \pm 0.2$ & $1.0 \pm 0.2$ & $0.10 \pm 0.02$ & $6.0 \times 10^{-4}$ \\
$500 \mathrm{kGy}$ in air & $5.6 \pm 0.5$ & $0.9 \pm 0.3$ & $0.05 \pm 0.02$ & $2.8 \times 10^{-4}$ \\
$100 \mathrm{kGy}$ in water & $5.4 \pm 0.1$ & $1.1 \pm 0.1$ & $0.10 \pm 0.02$ & $6.4 \times 10^{-4}$ \\
$200 \mathrm{kGy}$ in water & $6.2 \pm 0.1$ & $0.8 \pm 0.1$ & $0.08 \pm 0.01$ & $3.4 \times 10^{-4}$ \\
$500 \mathrm{kGy}$ in water & $7.2 \pm 0.2$ & $1.0 \pm 0.1$ & $0.09 \pm 0.01$ & $2.4 \times 10^{-4}$ \\
\hline
\end{tabular}

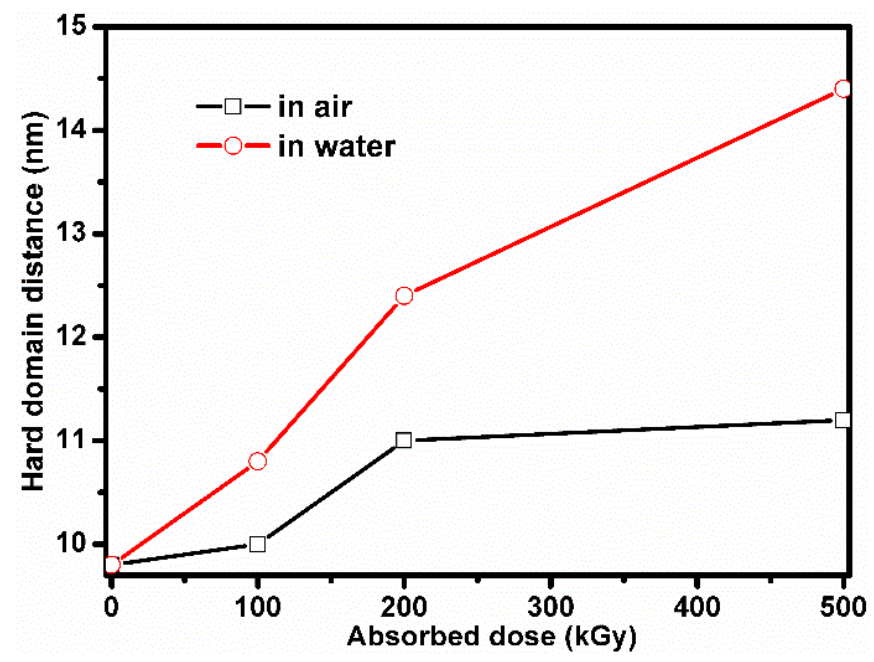

Figure 3. Variation of the hard domain distance $\left(2 R_{\mathrm{HS}}\right)$ with the absorbed dose, as obtained by SANS model fitting.

\subsection{Gel Permeation Chromatography (GPC)}

On the GPC chromatograms shown in Figure 4, the peak at $15 \mathrm{~mL}$ of elution volume is from the internal standard (toluene). The peak at $12.2 \mathrm{~mL}$ found for the original Estane corresponds to a molar mass of $20,000 \mathrm{~g} / \mathrm{mol}$. For the samples irradiated in air with a dose up to $100 \mathrm{kGy}$, the position of the peak remains constant, however, the peak intensity decreases. Simultaneously, a shoulder on the left side of the peak (at lower elution volume) is noticed. It can be concluded that a dose of less than $100 \mathrm{kGy}$ causes a conversion of a relatively small amount of original chains into larger linked structures. For a 
dose higher than $200 \mathrm{kGy}$, there is a slight shift of the peak to the right and also a significant increase of the signal at the left side of the peak corresponding to the formation of a large amount of linked structures with very high molar mass. Samples irradiated with a dose of $300 \mathrm{kGy}$ are still soluble in tetrahydrofuran (THF) however the samples irradiated with a dose up to $500 \mathrm{kGy}$ are insoluble in THF (it swells in THF, only). This occurs because cross-linking of PU chains exceeds a critical point when three-dimensional network structure of macroscopic size appears in the system. Therefore, the critical value of the dose for polymer network formation is somewhere between 300 and $500 \mathrm{kGy}$. For the samples irradiated in water, the situation is very similar to the samples irradiated in air. The only difference is that the shoulders at lower elution volume shift more to the left, indicative of the formation of longer chains.
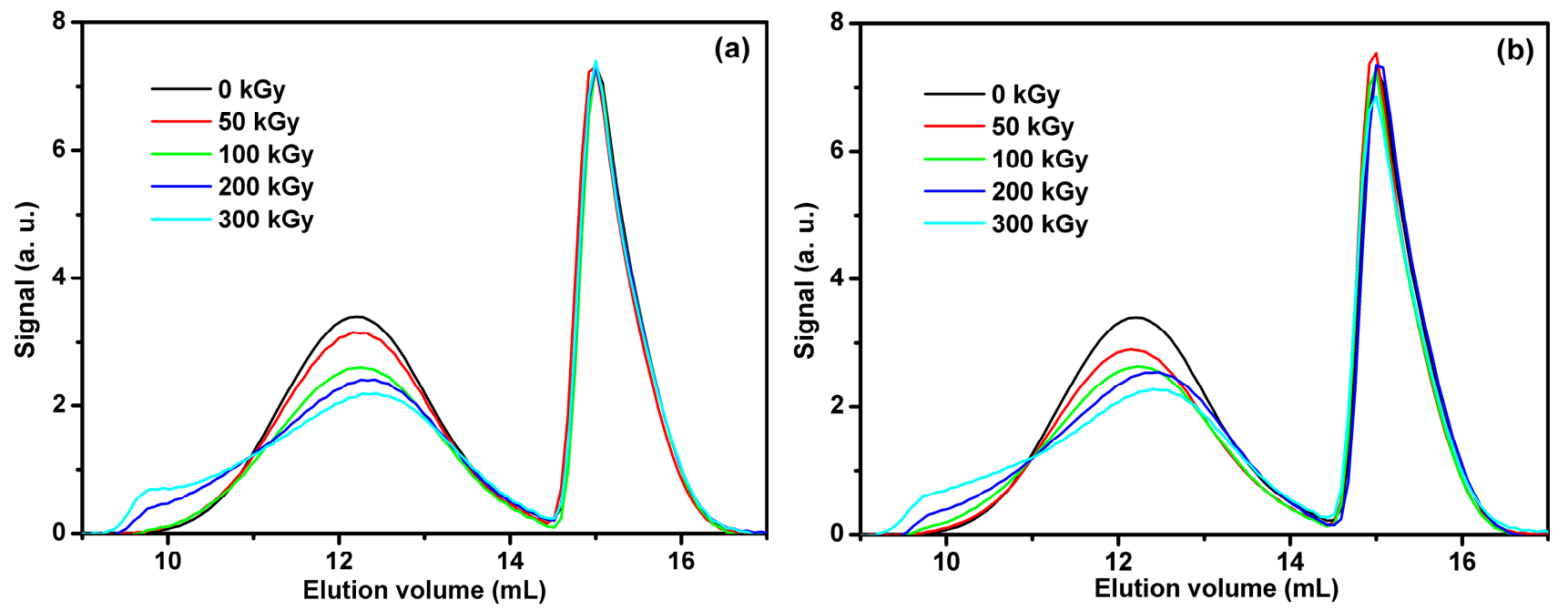

Figure 4. GPC curves of the Estane samples irradiated in air (a) and water (b).

\subsection{Fourier Transform Infrared Spectroscopy (FTIR)}

The microstructure of the irradiated Estane is further studied by FTIR for its sensitivity to the chemical changes, hydrogen bonding, and molecular chain packing in PUs. The FTIR spectra of the samples irradiated to $500 \mathrm{kGy}$ are shown in the region from 1000 to $1800 \mathrm{~cm}^{-1}$ in Figure 5. The absorption peak at $1414 \mathrm{~cm}^{-1}$ corresponds to the stable $\mathrm{C}-\mathrm{C}$ stretching vibration of the aromatic ring, and all the data are normalized to this peak [22]. The $\mathrm{CH}_{2}$ wagging vibration band at $1255 \mathrm{~cm}^{-1}$ shows a loss in intensity after irradiation to a dose of $500 \mathrm{kGy}$. It means that the number of $\mathrm{CH}_{2}$ groups is decreased because the $\gamma$ irradiation could generate the secondary alkyl radicals and the cross-linking occurs among the secondary alkyl radicals [5]. The IR bands centered at 1529 and $1216 \mathrm{~cm}^{-1}$ are assigned to the free $v(\mathrm{C}-\mathrm{N})+\delta(\mathrm{N}-\mathrm{H})$ in HSs [23]. Therefore, the increase of the two bands for the irradiated Estane can be attributed to the loss of inter-urethane H-bonds. That is, upon irradiation, the ordered molecular chain structures induced by H-bonds in HSs are destroyed.

\subsection{X-Ray Diffraction (XRD)}

The XRD patterns of the samples irradiated in air and water are shown in Figure 6. An amorphous halo and four diffraction peaks located at $9.4^{\circ}, 21.6^{\circ}, 22.4^{\circ}$ and $28.6^{\circ}$ are observed for all the samples. The only significant change observed in the series was the increase of the relative intensity of the 
peak at $21.6^{\circ}$, corresponding to a Bragg spacing of $4.11 \AA$, which relates to a certain degree of structural ordering upon irradiation. The $\alpha$-form monoclinic cell of pure PBA exhibits two characteristic (110) and (020) reflections centered at $21.75^{\circ}$ and $21.4^{\circ}[24,25]$, and the similar reflections from the SSs consisting of poly(ethylene adipate) or poly(tetramethylene adipate) are reported in [26,27]. Therefore, the results imply that the volume fraction of well-ordered SSs in Estane is increased induced by cross-linking.

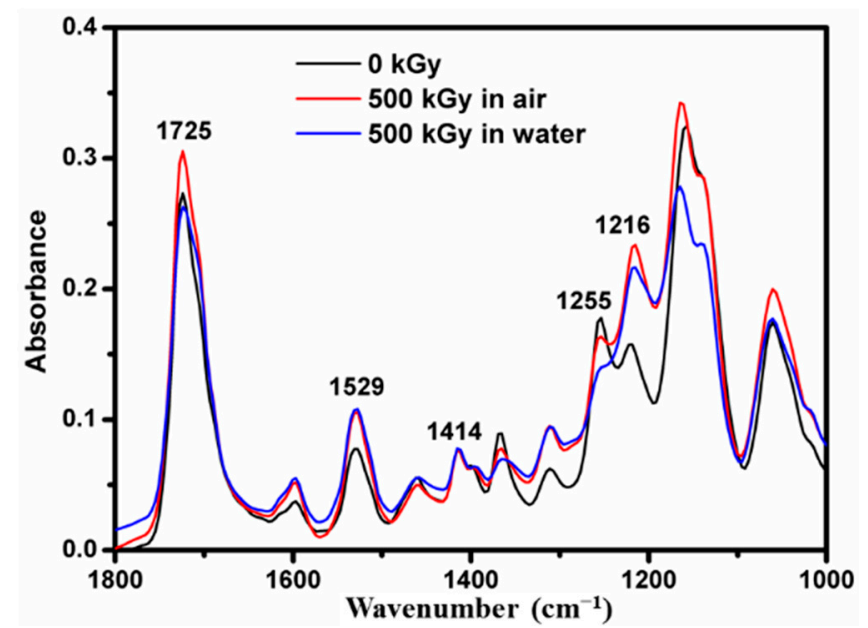

Figure 5. FTIR spectra of the Estane samples irradiated at the dose of $500 \mathrm{kGy}$ in air and water.

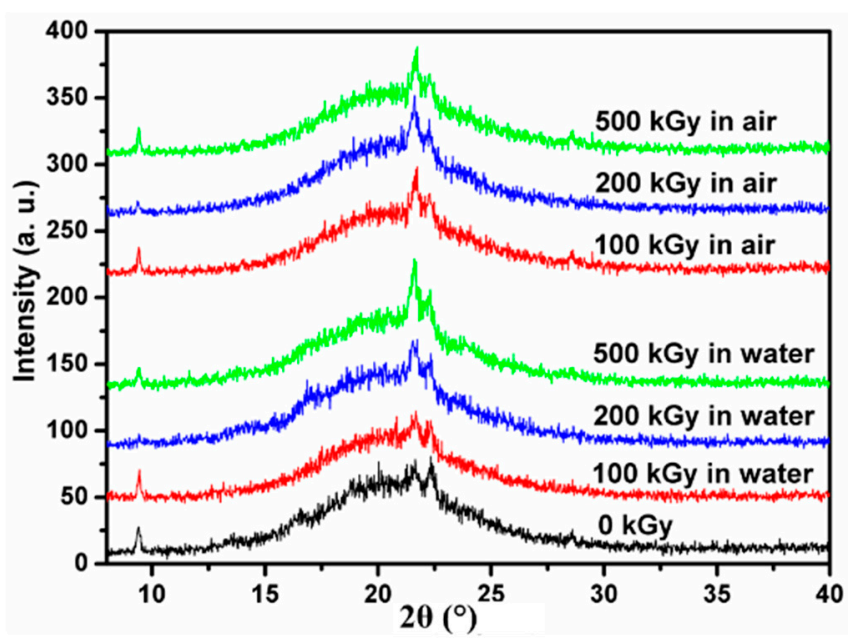

Figure 6. XRD patterns of the Estane samples irradiated at doses of 0, 100, 200 and $500 \mathrm{kGy}$ in air and water.

\section{Discussion}

\subsection{Phase Mixing Induced by $\gamma$ Irradiation}

The hard and soft domains in PUs are usually thermodynamically incompatible at ambient temperatures. The phase separation process is inhibited by steric and molecular mobility constraints. However, in the current work, the SANS results indicate that the $\gamma$ irradiation leads to an apparent increase of compatibility between the HSs and the SSs. It can be attributed to two factors. 
On one hand, the GPC results clearly show that samples irradiated both in air and water mainly undergo cross-linking. The secondary alkyl radicals $\left(\mathrm{R}-\mathrm{CH}_{2}-\mathrm{CH}_{2}-\dot{\mathrm{C}} \mathrm{H}-\mathrm{CH}_{2}-\mathrm{R}\right)$ induced by radiation undergo cross-linking, leading to new bonds between Estane molecules and bringing the molecules closer to each other. This process is shown as follows:

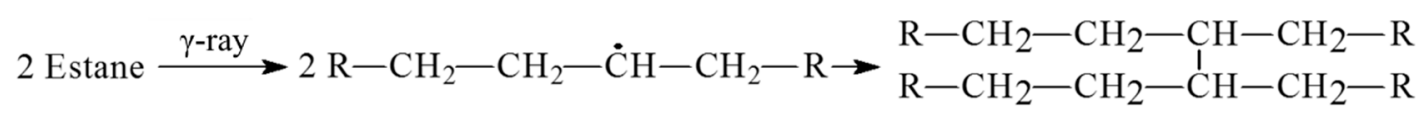

The above reaction can take place both in SSs (PBA) and HSs (BDO). The HSs volume fraction is much lower than SSs in Estane (Figure 1). Hence, the cross-linking occurred in SSs is the major reaction, resulting in the increase of the contractile force in SSs.

On the other hand, the $\gamma$ radiation may lead to the degradation of the HSs. It was reported that 4,4'-methylenedianiline (MDA) is produced in MDI-based PUs subjected to $\gamma$ irradiation with doses up to $100 \mathrm{kGy}$ [28]. It means that the irradiation cleaves the urethane linkage proximal to terminal amino groups. This chain scission reaction could result in the increase of chain mobility of HSs, and weaken the molecular interactions among hard domains. Therefore, it appears that an increase in the contractile force between the SSs induced by cross-linking tries to pull a part of HSs into the soft domain matrix and break down the hard domains. Smaller hard domains may be totally dissolved into the soft domains and then the average size of the hard domains would decrease. The thermodynamic driving force for the phase separation is gradually reduced with increasing dose. Hence, the degree of phase mixing in the irradiated Estane is enhanced, accompanied by the decrease of $a_{\text {cor }}$ and increase of $R_{\mathrm{HS}}$.

Morphological changes, such as phase separation or mixing of PUs induced by irradiation, are rarely reported. Murray et al. [6] and Huang et al. [29] studied the phase separation behavior of polyether PUs irradiated by electron beam. By using XRD and DSC techniques, their results showed an increase in phase separation during the exposure of irradiation. Walo et al. [30] studied the effects of HS/SSs composition on the structure and mechanical properties of polyester PUs exposed to electron beam irradiation. They assumed that the experimentally observed deterioration of the mechanical strength upon irradiation was related to the reduction of the degree of phase separation. In this work, we identified an increase of phase mixing in Estane exposed to $\gamma$-irradiation by analysis of SANS data of the domain sizes and distribution. Thus, the aging of PUs induced by irradiation is a complex process. Besides the chemical reactions (chain scission and cross-linking), the physical (morphological) changes are another important aspect of the aging process. Comparison with the above mentioned studies shows that the microstructure changes depend on the chemical composition and the type of PUs (polyester or polyether). Furthermore, the increase in the degree of phase mixing and the decrease in the number density of hard domains in Estane induced by $\gamma$-irradiation would result in the deterioration of mechanical properties due to the reduction of the number density of reinforce fillers (hard domains), as was shown in a recent study [31].

\subsection{The Effects of the Water and Air Environments}

Aqueous environment has specific effects on the microstructure of irradiated polymers. Highly reactive hydroxyl radicals $(\dot{\mathrm{O} H})$ can be generated in the radiolysis of water [32]. The hydroxyl radicals are capable of abstracting hydrogen atoms efficiently from Estane polymer chains. It follows that cross-linking should be highly favoured in aqueous media, i.e., 


$$
2 \text { Estane }+2 \dot{\mathrm{OH}} \longrightarrow 2 \mathrm{HOH}+2 \text { Estane } \bullet \longrightarrow \text { Estane-Estane }
$$

The degree of the cross-linking of Estane irradiated in water is higher than that irradiated in air. Accordingly, the samples irradiated in water exhibit more significant aging effects on the domain structures (Figure 3).

The carbonyl $\mathrm{C}=\mathrm{O}$ peak at $1725 \mathrm{~cm}^{-1}$ is increased for the sample irradiated in air, and remains nearly unchanged for the sample irradiated in water (Figure 5). Most possibly in the presence of $\mathrm{O}_{2}$, the alkyl radicals could react with the $\mathrm{O}_{2}$ to form peroxyl radicals, and subsequently transform to new carbonyls. Although the cross-linking is the main effect induced by irradiation, the alkyl radicals could also react with the $\mathrm{O}_{2}$. One possible reaction can be expressed as follows [33,34]:

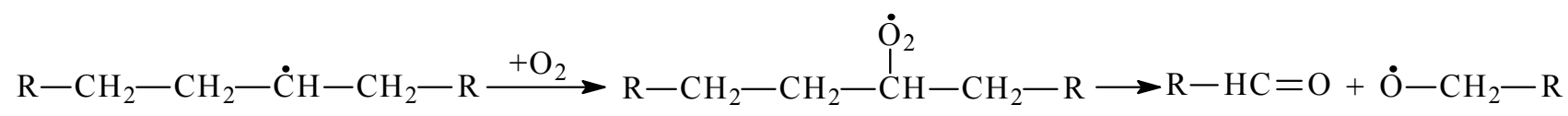

It has been reported that the increase of molecular weight of Estane irradiated in the absence of $\mathrm{O}_{2}$ is much larger than that irradiated in the presence $\mathrm{O}_{2}$ [5]. Consequently, the presence of $\mathrm{O}_{2}$ during irradiation results in chain scission reactions in Estane, counteracting the molecular weight increase caused by cross-linking.

\section{Conclusions}

The microstructure of Estane $\gamma$-irradiated in air and water was studied by SANS, GPC, FTIR, and XRD. The scattering data indicated that the degree of phase mixing in Estane was enhanced, the domain size decreased, and their separation increased after irradiation. The GPC results demonstrated progressive formation of larger crosslinked structures with very high molar mass with increasing absorbed dose. When the accumulated dose exceeded $300 \mathrm{kGy}$, the materials formed insoluble polymer networks. Compared with the samples irradiated in air, the samples irradiated in water exhibited stronger aging effects, as seen by an increase of phase mixing. The FTIR results suggested that the cross-linking occurred among the secondary alkyl radicals, and the $\mathrm{O}_{2}$ could react with alkyl radicals to form carbonyl bonds. The XRD results showed the volume fraction of well-ordered soft segments in Estane was increased upon irradiation.

\section{Acknowledgments}

This work was supported by project KMR12-1-2012-0226 granted by the National Development Agency of Hungary the National Natural Science Foundation of China under grant No. 11205137 and 11405152. We thank Éva Koczog for sample preparation and IR measurements.

\section{Author Contributions}

All listed authors contributed to the research work. László Almásy and László Rosta conceived and directed the research project; László Almásy performed the SANS experiments; Qiang Tian and László Almásy proposed ideas for data explanation and wrote the paper; Erzsébet Takács conducted the $\gamma$ irradiation and FTIR analysis; Ivan Krakovský did the GPC measurements and analysis; Zsolt Endre Horváth did the XRD measurements. 


\section{Conflicts of Interest}

The authors declare no conflict of interest.

\section{References}

1. Prisacariu, C. Polyurethane Elastomers: From Morphology to Mechanical Aspects; Springer Verlag: Wien, Austria, 2011; pp. 3-16.

2. Kusano, J.; Uno, Y. Radiation resistivity of polymeric materials with data tables. Available online: http://jolissrch-inter.tokai-sc.jaea.go.jp/pdfdata/JAERI-Data-Code-2003-015.pdf (accessed on 5 September 2015).

3. Adem, E.; Angulo-Cervera, E.; González-Jiménez, A.; Valentín, J.L.; Marcos-Fernández, A. Effect of dose and temperature on the physical properties of an aliphatic thermoplastic polyurethane irradiated with an electron beam. Radiat. Phys. Chem. 2015, 112, 61-70.

4. Shintani, H.; Kikuchi, H.; Nakamura, A. Effects of gamma ray irradiation on the change of characteristics of polyurethane. J. Appl. Polym. Sci. 1990, 41, 661-675. [CrossRef]

5. Pierpoint, S.; Silverman, J.; Al-Sheikhly, M. Effects of ionizing radiation on the aging of polyester based polyurethane binder. Radiat. Phys. Chem. 2001, 62, 163-169. [CrossRef]

6. Murray, K.A.; Kennedy, J.E.; McEvoy, B.; Vrain, O.; Ryan, D.; Cowman, R.; Higginbotham, C.L. The influence of electron beam irradiation conducted in air on the thermal, chemical, structural and surface properties of medical grade polyurethane. Eur. Polym. J. 2013, 49, 1782-1795. [CrossRef]

7. Burillo, G.; Beristain, M.F.; Sanchez, E.; Ogawa, T. Effects of aromatic diacetylenes on polyurethane degradation by gamma irradiation. Polym. Degrad. Stab. 2013, 98, 1988-1992. [CrossRef]

8. Sui, H.; Liu, X.; Zhong, F.; Li, X.; Wang, B.; Ju, X. Relationship between free volume and mechanical properties of polyurethane irradiated by gamma rays. J. Radioanal. Nucl. Chem. 2014, 300, 701-706. [CrossRef]

9. Wang, C.B.; Cooper, S.L. Morphology and properties of segmented polyether polyurethaneureas. Macromolecules 1983, 16, 775-786. [CrossRef]

10. Li, Y.; Gao, T.; Liu, J.; Linliu, K.; Desper, C.R.; Chu, B. Multiphase structure of a segmented polyurethane: Effects of temperature and annealing. Macromolecules 1992, 25, 7365-7372. [CrossRef]

11. Sui, T.; Baimpas, N.; Dolbnya, I.P.; Prisacariu, C.; Korsunsky, A.M. Multiple-length-scale deformation analysis in a thermoplastic polyurethane. Nat. Commun. 2015, 6, 6583. [CrossRef] [PubMed]

12. Laity, P.R.; Taylor, J.E.; Wong, S.S.; Khunkamchoo, P.; Norris, K.; Cable, M.; Andrewsc, G.T.; Johnsonb, A.F.; Cameron, R.E. A review of small-angle scattering models for random segmented poly(ether-urethane) copolymers. Polymer 2004, 45, 7273-7291. [CrossRef]

13. Mang, J.T.; Peterson, P.D.; Orler, E.B.; Wrobleski, D.A.; Langlois, D.A.; Espada, L.I.; Hjelm, R.P. Small-angle neutron scattering study of a thermally aged, segmented poly(ester urethane) binder. Neutron News 2003, 14, 26-28. [CrossRef] 
14. Koberstein, J.T.; Russell, T.P. Simultaneous SAXS-DSC study of multiple endothermic behavior in polyether-based polyurethane block copolymers. Macromolecules 1986, 19, 714-720. [CrossRef]

15. Taylor, J.E.; Laity, P.R.; Freeburn, S.; Wong, S.S.; Norris, K.; Khunkamchoo, P.; Andrews, G.; Johnson, A.F.; Cameron, R.E. Effect of processing route and acetone pre-treatment on the biostability of pellethane materials used in medical device applications. Biomaterials 2005, 26, 6467-6476. [CrossRef] [PubMed]

16. Tian, Q.; Almásy, L.; Yan, G.; Sun, G.; Zhou, X.; Liu, J.; Rosta, L.; Chen, B. Small-angle neutron scattering investigation of polyurethane aged in dry and wet air. Express Polym. Lett. 2014, 8, 345-351. [CrossRef]

17. Keiderling, U. The new "BerSANS-PC" software for reduction and treatment of small angle neutron scattering data. Appl. Phys. A 2002, 74, s1455-s1457. [CrossRef]

18. Breßler, I.; Kohlbrecher, J.; Thünemann, A.F. SASfit: A comprehensive tool for small-angle scattering data analysis. Available online: http://arxiv.org/ftp/arxiv/papers/1506/1506.02958.pdf (accessed on 5 September 2015).

19. Debye, P.; Anderson, R.; Brumberger, H. Scattering by an inhomogeneous solid. II. The correlation function and its application. J. Appl. Phys. 1957, 28, 679-683. [CrossRef]

20. Krakovský, I.; Bubenikova, Z.; Urakawa, H.; Kajiwara, K. Inhomogeneous structure of polyurethane networks based on poly(butadiene)diol: 1 . The effect of the poly(butadiene)diol content. Polymer 1997, 38, 3637-3643. [CrossRef]

21. Linliu, K.; Chen, S.A.; Yu, T.L.; Lin, T.L.; Lee, C.H.; Kai, J.J.; Chang, S.L.; Lin, J.S. A small-angle X-ray scattering study of microphase separation transition of polyurethanes: Effect of hard segments. J. Polym. Res. 1995, 2, 63-70. [CrossRef]

22. Deng, Y.W.; Yu, T.L.; Ho, C.H. Effect of aging under strain on the physical properties of polyester-urethane elastomer. Polym. J. 1994, 26, 1368-1376. [CrossRef]

23. Schoonover, J.R.; Thompson, D.G.; Osborn, J.C.; Orler, E.B.; Wrobleski, D.A.; Marsh, A.L.; Wang, H.; Ralmer, R.A. Infrared linear dichroism study of a hydrolytically degraded poly(ester urethane). Polym. Degrad. Stab. 2001, 74, 87-96. [CrossRef]

24. Wang, H.J.; Feng, H.P.; Guo, P.Y.; Zhao, T.S.; Ren, L.F.; Qiang, X.H.; Xiang, Y.H. Effects of crystallization temperature and blend ratio on the crystal structure of poly(butylene adipate) in the poly(butylene adipate)/poly(butylene succinate) blends. Chin. J. Polym. Sci. 2014, 32, 488-496. [CrossRef]

25. Gan, Z.; Kuwabara, K.; Abe, H.; Iwata, T.; Doi, Y. Metastability and transformation of polymorphic crystals in biodegradable poly(butylene adipate). Biomacromolecules 2004, 5, 371-378. [CrossRef] [PubMed]

26. Kovačević, V.; Šmit, I.; Hace, D.; Sućeska, M.; Mudri, I.; Bravar, M. Role of the polyurethane component in the adhesive composition on the hydrolytic stability of the adhesive. Int. J. Adhes. Adhes. 1993, 13, 126-136. [CrossRef]

27. Blackwell, J.; Nagarajan, M.R.; Hoitink, T.B. Structure of polyurethane elastomers. X-ray diffraction and conformational analysis of MDI-propandiol and MDI-ethylene glycol hard segments. Polymer 1981, 22, 1534-1539. [CrossRef] 
28. Shintani, H.; Nakamura, A. Formation of 4,4'-methylenedianiline in polyurethane potting materials by either $\gamma$-ray or autoclave sterilization. J. Biomed. Mater. Res. 1991, 25, 1275-1286. [CrossRef] [PubMed]

29. Huang, W.; Xiong, J.; Chen, X.; Gao, X.; Xu, Y.; Fu, Y. Study on the radiation degradation of polyether-polyurethane induced by electron beam. J. Radioanal. Nucl. Chem. 2007, 274, 525-530.

30. Walo, M.; Przybytniak, G.; Łyczko, K.; Piątek-Hnat, M. The effect of hard/soft segment composition on radiation stability of poly(ester-urethane)s. Radiat. Phys. Chem. 2014, 94, 18-21. [CrossRef]

31. Yanagihara, Y.; Osaka, N.; Iimori, S.; Murayama, S.; Saito, H. Relationship between modulus and structure of annealed thermoplastic polyurethane. Mater. Today Commun. 2015, 2, e9-e15. [CrossRef]

32. Von Sonntag, C.; Bothe, E.; Ulanski, P.; Adhikary, A. Radical transfer reactions in polymers. Radiat. Phys. Chem. 1999, 55, 599-603. [CrossRef]

33. Chapiro, A. Radiation chemistry of polymers. Radiat. Res. Suppl. 1964, 4, 179-191. [CrossRef]

34. Pârvu, R.; Podina, C.; Zaharescu, T.; Jipa, S. Stability evaluation of polyurethane coatings by gamma irradiation. Optoelectron. Adv. Mater. Rapid Commun. 2010, 4, 1815-1818.

(C) 2015 by the authors; licensee MDPI, Basel, Switzerland. This article is an open access article distributed under the terms and conditions of the Creative Commons Attribution license (http://creativecommons.org/licenses/by/4.0/). 